\title{
Tobias Herbst
}

\section{Gesetzgebungskompetenzen im Bundesstaat}

\author{
Eine Rekonstruktion der Rechtsprechung des Bundesverfassungsgerichts
}

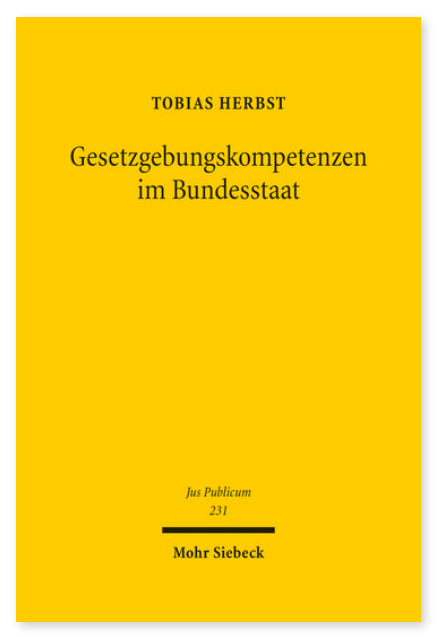

2014. XVI, 412 Seiten. JusPubl 231

ISBN 978-3-16-153025-8

DOI 10.1628/978-3-16-153025-8

eBook PDF 134,00€

ISBN 978-3-16-151996-3

Leinen $134,00 €$
Die Rechtsprechung des Bundesverfassungsgerichts zu den Gesetzgebungskompetenzen hat bis heute einen eher kasuistischen Charakter. Tobias Herbst unternimmt eine Rekonstruktion dieser Rechtsprechung und eine Systematisierung der Kompetenzabgrenzung: Im Zentrum der Betrachtung stehen dabei nicht die Einzelkompetenzen in ihrer Vielfalt, sondern die methodischen und dogmatischen Gemeinsamkeiten bei deren Abgrenzung im Konfliktfall. Das Spektrum der behandelten Fragen umfasst unter anderem den Stellenwert der historischen Methode bei der Auslegung von Kompetenznormen, die Kompetenzneutralität des materiellen Verfassungsrechts, die Berücksichtigung des Kontextes einer Regelung bei ihrer kompetentiellen Qualifikation, die Auflösung von Kompetenzkonkurrenzen, »ungeschriebene« Kompetenzen, materiellrechtliche Kompetenzausübungsschranken sowie den kompetenzbezogenen Einschätzungsspielraum des Gesetzgebers.

Tobias Herbst Geboren 1963; Studium der Rechtswissenschaft in Würzburg; 2002 Promotion; 2010 Habilitation; seither Lehrstuhlvertretungen in Augsburg, Bielefeld und Frankfurt am Main, zugleich Privatdozent an der Humboldt-Universität zu Berlin.
Jetzt bestellen:

https://mohrsiebeck.com/buch/gesetzgebungskompetenzen-im-bundesstaat-9783161530258?no_cache=1 order@mohrsiebeck.com

Telefon: $+49(0) 7071-923-17$

Telefax: $+49(0) 7071-51104$ 